\title{
Impact of Lutein Intervention in Mice on the Radiation Induced Clastogenic Changes
}

Vidya Vasudeva ${ }^{1}$, Yogish Somayaji Tenkanidiyoor ${ }^{2}$, Vishakh Radhakrishna ${ }^{1}$, Alex Peter ${ }^{3}$, Jayaram Shetty ${ }^{3}$, Shrikant Patil ${ }^{1}$, Krishna Patali ${ }^{1}$, Ronald Fernandes $^{4^{*}}$

\author{
${ }^{1}$ Nitte University K S Hegde Medical Academy; \\ ${ }^{2}$ St. Aloysius College (Autonomous), PG Department of Biochemistry; \\ ${ }^{3}$ Leela Narayan Shetty Memorial Cancer Institute; \\ ${ }^{4}$ Nitte Gulabi Shetty Memorial Institute of Pharmaceutical Sciences, \\ Department of Biochemistry.
}

* Correspondence: Dr. Ronald Fernandes, Professor, Department of Biochemistry, Nitte Gulabi Shetty Memorial Institute Of Pharmaceutical Sciences, Nitte University, Paneer, Deralakatte, Mangalore, India. Email: ronaldfernandesv@gmail.com.

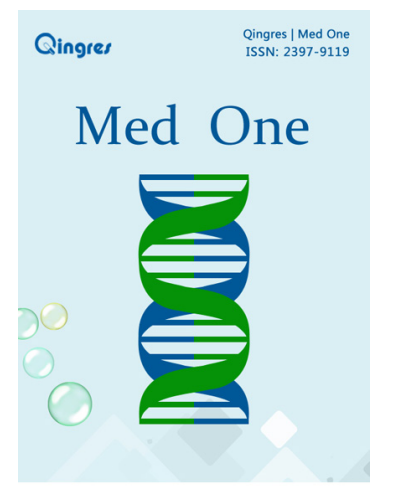

http://mo.qingres.com

\section{GOPEN ACCESS}

DOI: $10.20900 / \mathrm{mo} .20170022$

Received: July 16, 2017

Accepted: September 18, 2017

Published: October 25, 2017

Copyright: $\odot 2017$ Cain et al. This is an open access article distributed under the terms of the Creative Commons Attribution License, which permits unrestricted use, distribution, and reproduction in any medium, provided the original author and source are credited.

\begin{abstract}
One of the genetic effects of radiation is that it may lead to formation of single or double strand breaks in DNA which can be observed in differentially stained polychromatic or normochromatic erythrocytes (PCE and NCE respectively). In pursuit of finding a natural radioprotector to treat the radiation induced damages; lutein, a carotenoid pigment is one such approach. Swiss albino mice are administered with the compound (lutein/gallic acid/DMSO) with respective controls for 15 consecutive days after which they are irradiated. The whole blood is drawn for comet assay and the femur of the leg is removed to flush out the content of the bone marrow in BSA for the micronucleus assay. The comet slides are observed under the fluorescent microscope and the PCE/NCE or micronucleated PCEs or NCEs are scored blindly. Lutein in the present study has effectively reduced the olive moment and the tail moment. However, $\%$ DNA in tail has been maintained to normal levels in comparison to its control indicating lesser extent of damage to the genetic material. The percent micronucleated NCE (MnNCE) has been decreased in the group treated with lutein prior to radiation. The \%MnPCE and the PCE/ (PCE + NCE) ratio has been increased in all the irradiated groups; however lutein treatment has not drastically increased the formation of micronuclei in comparison to its control. This indicates that lutein shows a protective effect against the radiation induced cytogenetic damages in Swiss albino mice.
\end{abstract}


Keywords: Electron beam radiation; Strand breaks; Comet assay; Micronuclei

\section{INTRODUCTION}

Radiation is increasingly used for medical and occupational purposes and is an established weapon in the diagnosis and the therapy of cancer. Radiation therapy injures or destroys cells in the area being treated (or "target tissue") by damaging their genetic material. So the amount of ionizing radiation that can be given to treat malignant tumors are limited ${ }^{[1,}$ ${ }^{2]}$. Free radicals are unstable molecules which react easily with essential molecules of our body including DNA, fat and proteins changing their chemical structure. When a free radical attacks a molecule, it will then become a free radical itself, causing a chain reaction which can result in the destruction of a cell ${ }^{[3]}$. The goal of the radiation therapy is to minimize the dose delivered to normal cells or tissues thus reducing the damage and maximize the dose effect to tumor cells ${ }^{[4]}$.

Electron beam radiation (EBR) has a unique place in the field of radiation oncology especially in the treatment of skin cancer.

Lutein is a xanthophyll; carotenoid pigment present abundantly in kale, spinach, corn, animal fat etc. In a study by Neal Craft $E^{[5]}$, it was found that lutein is soluble in dimethyl sulfoxide (DMSO), $1000 \mathrm{mg} / \mathrm{L}$. Lutein exhibits antigenotoxic ${ }^{[6]}$, antioxidant ${ }^{[7]}$ property, reduces ultraviolet radiation induced inflammation and immunosuppression ${ }^{[8]}$, chemopreventive activity in mouse models ${ }^{[9]}$, protects against age-related macular degeneration ${ }^{[10]}$. The present study aims at understanding the protective property of lutein against EBR induced damage to the genetic material and the immature, mature lymphocytes; polychromatic erythrocytes and normochromatic erythrocytes (PCEs and NCEs respectively).

\section{MATERIALS AND METHODS}

Lutein was purchased from Hai Hang Industry Pvt Ltd; China. All the other chemicals were purchased from Hi Media pvt. Itd.

Radiation to Swiss albino mice was given at Dept of Oncology, Justice K S Hegde Hospital, Mangalore. The mice were placed in well ventilated perspex box with dimensions 3' $\times 6$ '. Sub-lethal dose of $6 \mathrm{~Gy}$ was given at a dose rate of $3 \mathrm{~Gy} / \mathrm{min}$ with source to target distance of $100 \mathrm{cms}$.
The mice were orally administered with the compound for 15 days and on the 15th day one hour after administration of the compound the mice were sacrificed by anesthetizing and the whole blood was drawn into $2 \%$ EDTA tubes to perform comet assay. Femur of leg was removed and bone marrow was flushed carefully for micronucleus assay.

\subsection{Comet assay ${ }^{[11]}$}

The slides were coated with $1 \%$ high melting agarose (HMA) onto which a layer of about $20 \mu \mathrm{l}$ of the whole blood mixed with $80 \mu$ l of $0.5 \%$ low melting agarose (LMA) in PBS at $37^{\circ} \mathrm{C}$ was added and covered with a coverslip and was kept at $4^{\circ} \mathrm{C}$ for at least 5 mins. The coverslip was removed and a layer of HMA is added again to ensure no or minimal loss of sample in further process. After removing the coverslip, the slides were submerged overnight in cold lysing solution containing $2.5 \mathrm{M} \mathrm{NaCl}, 100 \mathrm{mM}$ EDTA disodium salt, $10 \mathrm{mM}$ Tris- $\mathrm{HCl}, 200 \mathrm{mM} \mathrm{NaOH}$, $1 \%$ Triton X-100, and $10 \%$ DMSO. Slides were then immersed in alkaline electrophoresis buffer $(0.3 \mathrm{M}$ $\mathrm{NaOH}$ and $1 \mathrm{mM}$ EDTA disodium salt, $\mathrm{pH}>13$ ) and then electrophoresed (20V/400mA, 24min). Slides were neutralized in neutralizing buffer (Tris buffer, $\mathrm{pH}-7.5$ ) for 5 minutes each with 2-3 repetitions. The loops of DNA extend towards anode which when stained with ethidium bromide and viewed under a fluorescent microscope gives the appearance like the tail of a comet. The undamaged DNA remains within the head of the comet and the damaged DNA (lysed DNA) appear towards the tail. To evaluate the degree of damage, comet images were scored with CometScore software. Duplicates were maintained for each sample. Fifty cells per slide were examined.

\subsection{Micronucleus assay ${ }^{[12]}$}

The bone marrow was flushed out into freshly prepared $5 \%$ bovine serum albumin solution (BSA solution prepared in PBS). The tubes were centrifuged at $1,000 \mathrm{rpm}$ for $10 \mathrm{mins}$. The pellet is resuspended in $100 \mu \mathrm{L}$ BSA and mixed carefully. A small drop was dropped on to a clean glass slide and smear was prepared. The slide was allowed to dry which was then fixed in methanol and stained with May Grunwald, Giemsa stain following each step for 2-3, 4 and 20 minutes respectively. The excess stain in each staining step was removed by dipping it for a few seconds in distilled water. The slides were scored blindly for polychromatic erythrocytes (PCE) and normochromatic erythrocytes (NCE), stained purple and pink respectively using a light microscope with 100X magnification (oil immersion). The micronucleated PCEs (MNPCE) and NCEs (MNNCE) were also recorded. In order to evaluate the cytotoxic effects of electron beam radiation and lutein against bone marrow proliferation PCE/PCE + 
NCE ratio was calculated.

\subsection{Dose reduction factor (DRF) ${ }^{[13]}$}

Dose reduction factor is the ratio of survival of mice with and without the compound being administered prior irradiation with a high dose of radiation. The mice were treated with lutein for 15 consecutive days and then irradiated with higher doses of $8 \mathrm{~Gy}, 9 \mathrm{~Gy}$ and 10Gy EBR. The radiation dose at which $50 \%$ survival is observed is compared with the radiation dose of the control group without any intervention and expressed as ratio.

$$
\mathrm{DRF}=\frac{\mathrm{LD} 50 / 30 \text { with compound }}{\text { LD 50/30 without compound }}
$$

\section{RESULTS}

\subsection{Comet assay}

Olive moment was increased in the radiation control group when compared to normal control $(p<0.05)$. The irradiated groups that were pretreated with gallic acid and lutein reduced the olive moment in comparison to their control $(p<0.05)$ (Fig.1 and Fig.2).

The percentage DNA in tail was higher in the radiation control group in comparison to its respective control $(p<0.001)$. Gallic acid pretreatment before irradiation reduced the percentage DNA in tail significantly $(p<0.05)$.

The tail moment was significantly reduced in the irradiated group pretreated with $250 \mathrm{mg} / \mathrm{kg}$ b.wt lutein $(p<0.001)$.

These results indicate that lutein treatment reduced the DNA damage that was induced by radiation.
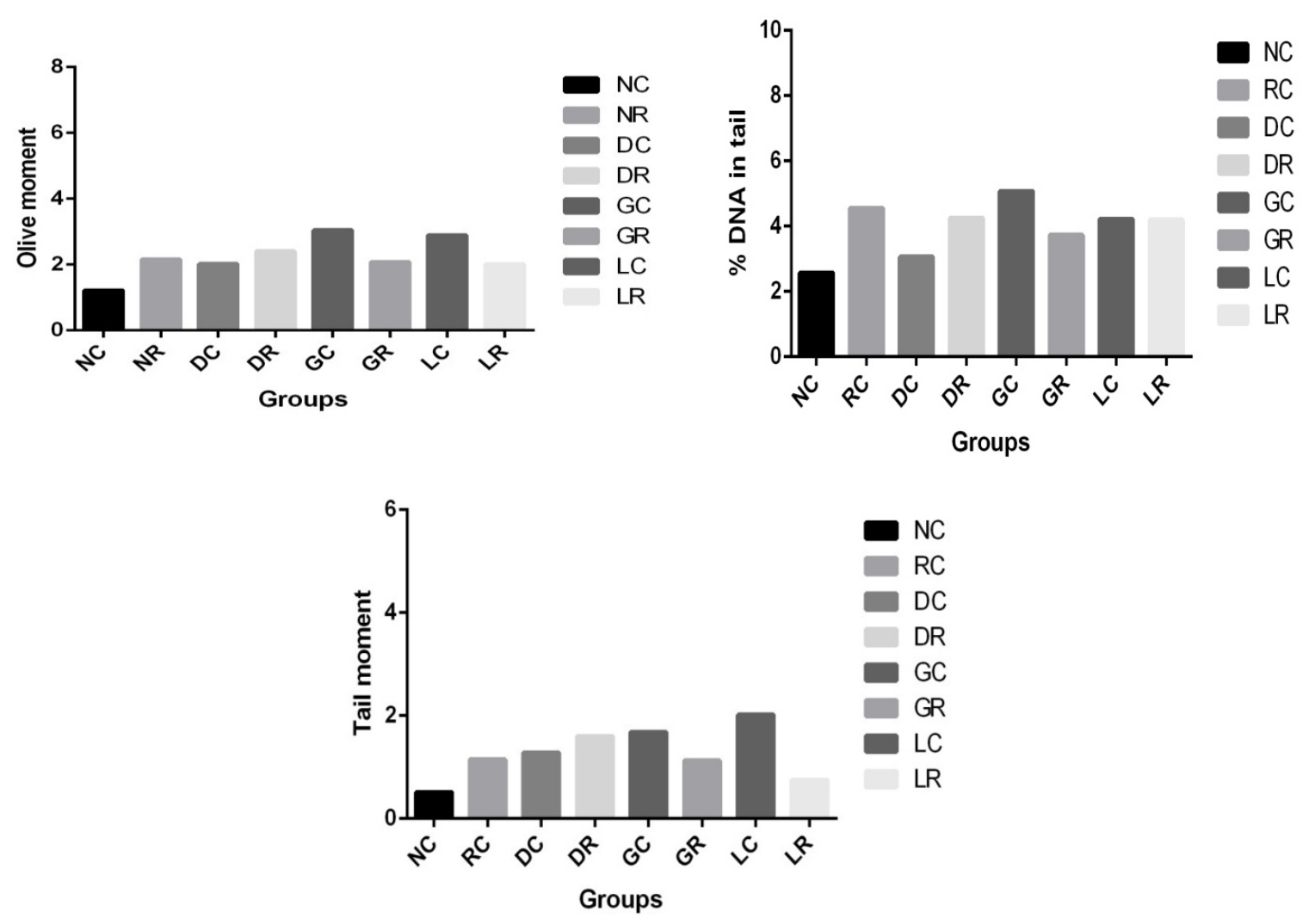

Fig. 1 showing the results for extent of DNA damage evaluated by comet assay.

$\mathrm{NC}=$ Normal control, $\mathrm{RC}(/ \mathrm{NR})=$ Normal radiation control, GC=Gallic acid control, $\mathrm{GR}=$ irradiated group that was pretreated with gallic acid, DC= DMSO control, DR= radiated group pretreated with DMSO, LC= Lutein control, $\mathrm{LR}=$ Lutein pretreated group. 


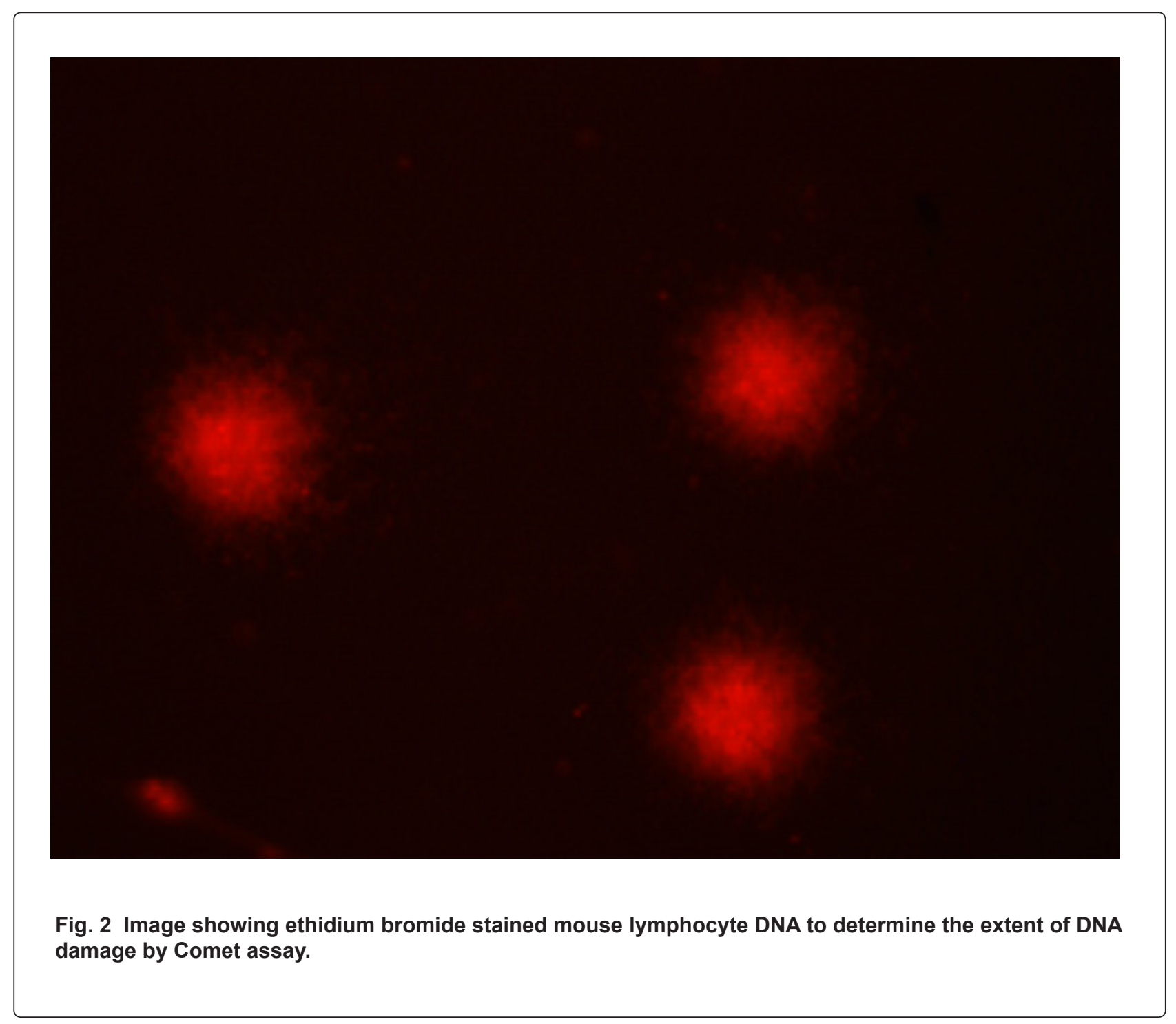

\subsection{Micronucleus assay}

Table 1 summarizes the micronucleus assay with lutein, gallic acid and $10 \%$ DMSO treatment prior irradiation with their corresponding controls (Fig. 3). A significant increase $(p<0.001)$ in MNPCE was seen in the radiation control in comparison to the untreated group. The ratio of MNPCE and MNNCE was also altered in the radiation control when

compared to the untreated group. The reduction in the number of MnPCE, MnNCE and MnPCE/ MnNCE ratio was found in gallic acid and lutein pretreatment prior irradiation, but the differences were not statistically significant when compared with the radiation control group. 


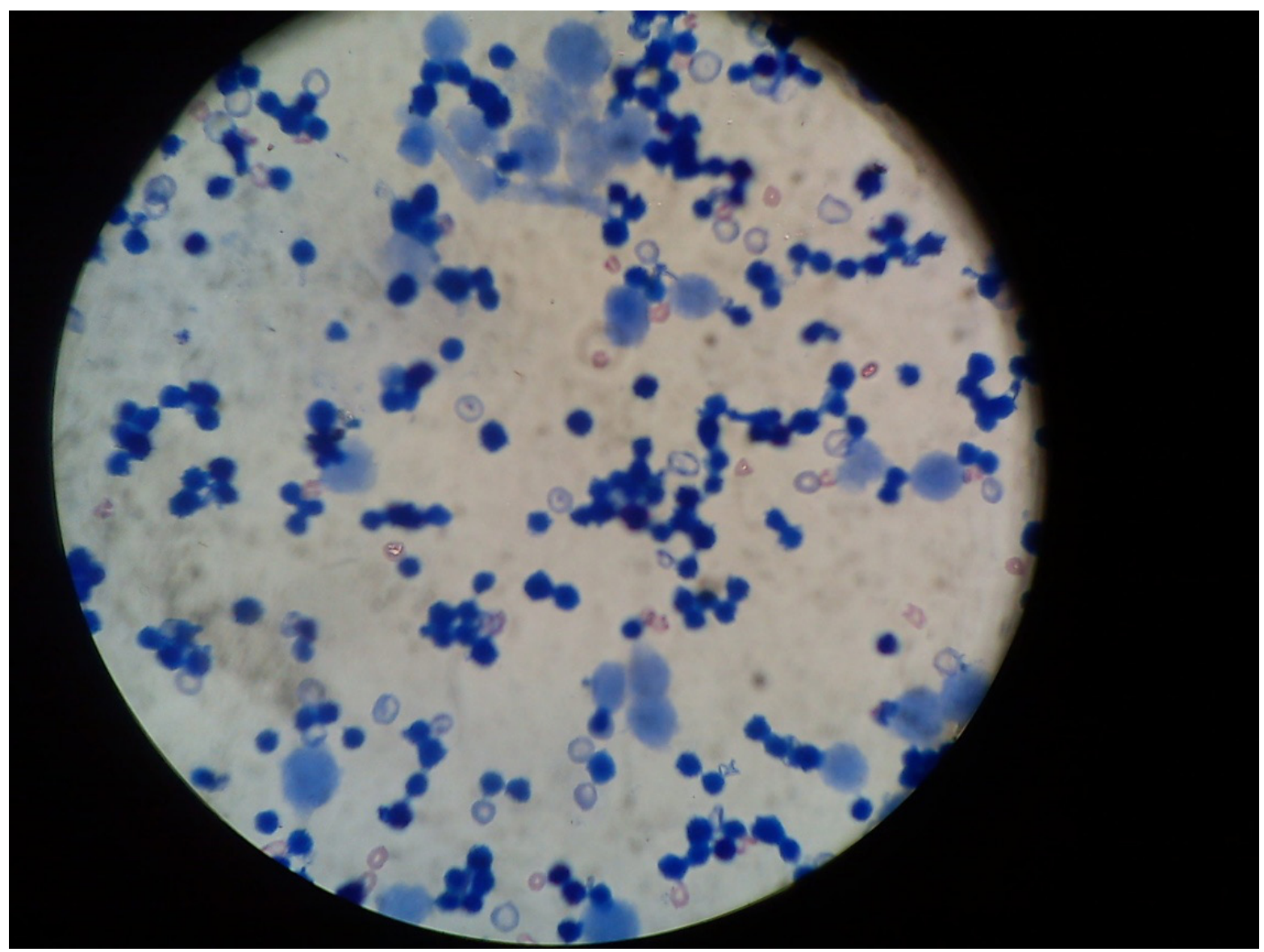

Fig. 3 Image showing Giemsa-May Grunwald stained mouse bone marrow with pink coloured normochromic erythrocytes (NCE) and purple coloured polychromatic erythrocytes (PCE) and micronucleated NCE or PCE appearing as a dot towards the membane.

Table 1. Results of micronucleus assay

\begin{tabular}{cccc}
\hline Groups & MnPCE $(\%)$ & MnNCE $(\%)$ & PCE/(PCE + NCE) (Mean \pm SD) \\
\hline NC & 1.63 & 0.88 & $0.45 \pm 0.02$ \\
NR & 7.63 & 1.38 & $0.74 \pm 0.03$ \\
GC & 4 & 1 & $0.49 \pm 0.02$ \\
GR & 9.93 & 0.62 & $0.8 \pm 0.02$ \\
DC & 5.25 & 1 & $0.56 \pm 0.02$ \\
DR & 8 & 1.13 & $0.79 \pm 0.06$ \\
LC & 4.25 & 1.25 & $0.55 \pm 0.03$ \\
LR & 6.75 & 0.25 & $0.9 \pm 0.01$
\end{tabular}

$\mathrm{NC}=$ Normal control, NR =Normal radiation control, GC = Gallic acid control, GR $=$ irradiated group that was pretreated with gallic acid, DC = DMSO control, DR = radiated group pretreated with DMSO, LC = Lutein control, LR = Lutein pretreated group. 


\subsection{Dose reduction factor}

DRF for lutein $=8.6 / 7.8$

$\mathrm{DRF}=1.102$
The dose reduction factor thus obtained for lutein is 1.102. (Fig. 4)

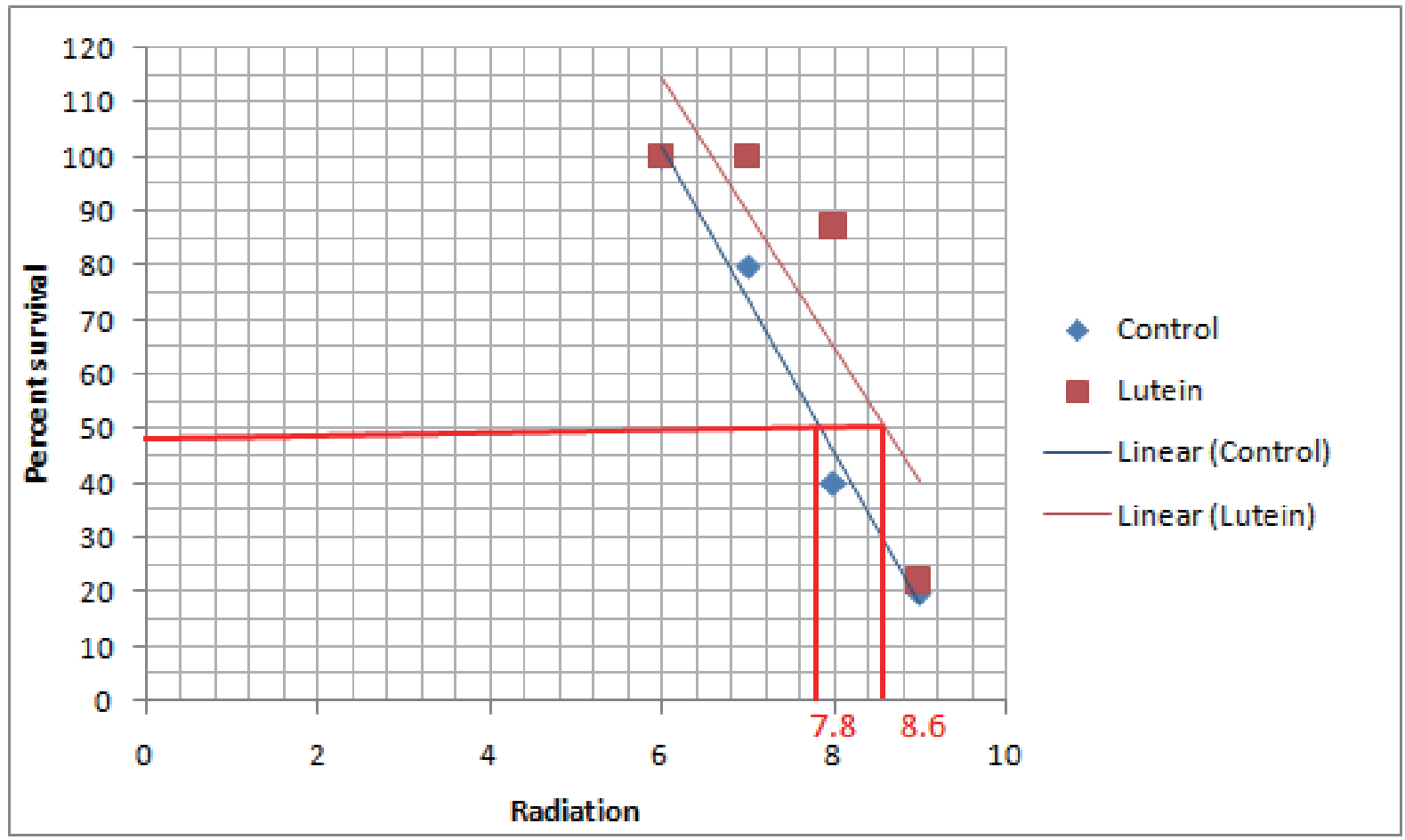

Fig. 4 Graph showing the LD50 of lutein and control without any intervention.

\section{DISCUSSION}

IR can directly induce DNA damage by causing strand breaks or indirectly induce DNA damage by producing reactive oxygen species such as superoxide anions and hydrogen peroxide ${ }^{[13]}$.

Olive tail moment, \% DNA in tail and tail moment are important factors assessed to evaluate the damage caused to DNA ${ }^{[14]}$. Irradiation to mice shows a drastic increase in these parameters indicating damage to genetic material ${ }^{[15]}$. Our study also revealed damage to genetic material in the irradiated group that is indicated by a significant increase in the olive moment and the percent DNA in tail, which was recovered within $24 \mathrm{hrs}$ in the lutein treated group to near normal system. Further the tail moment was significantly decreased in the group pretreated with lutein indicating that lutein shows a protective effect against damage to the genetic material.
Formation of $\mathrm{MN}$ is a result of cytogenetic damage which is evaluated by scoring the differentially stained cells in micronucleus assay. It is a cytogenetic method which is used to assess the cytotoxic effects of chemical materials or irradiation in diverse system. The presence of toxic agent in a system affecting the bone marrow proliferation will increase the number of PCE, i.e. the immature erythrocyte in comparison to NCE i.e. the mature erythrocytes. The toxicity of the agent in a biological system decreases the PCE/ NCE ratio ${ }^{[16]}$. Acute radiation exposure in humans induces $\mathrm{MN}$ formation. Its frequency is affected by radiation dose ${ }^{[17]}$. Fenech showed an increased MN frequency in human lymphocytes after exposure to 50-500 Msv range of IR ${ }^{[12]}$. MN represents chromosomal fragments left behind when the reticulocyte ejects its nucleus ${ }^{[18]}$. The number of 
nucleated RBC (nRBC), micronucleated RBC (also called Howell-Jolly bodies) (or both) may increase in response to diseases causing anemia, inadequate splenic function, or myelodysplastic syndrome and myeloproliferative disorders ${ }^{[18,19]}$. In the present study increased $\mathrm{MN}$ formation in the radiation control and a normalized levels in the lutein and gallic acid treatment prior irradiation indicate a potential anticlastogenic effect of lutein in vivo.

The most important effect of any radioprotective compound is its ability to enhance the survival and reduce the mortality ${ }^{[20]}$. The effectiveness of radiation protection expressed in terms of enhancing the survival can be done by comparing the increase in radiation dosage required to reduce the survival by $50 \%$ to that of the dosage without the presence of the compound ${ }^{[13]}$. This is given as a ratio as termed as the Dose reduction factor (DRF). The most effective drug, amifostine has a DRF of 2.5 which means the radiation dosage required to reduce the survival to $50 \%$ is 2.5 times higher than the dose required without the compound ${ }^{[20]}$. The measurement of DRF has become one of the mandatory parameters in the development of radio-protective agents as it provides a characteristic feature of a compounds ability to enhance survival. A DRF value

\section{REFERENCES}

1. Nunia V, Sancheti G, Goyal PK. Protection of Swiss albino mice against whole-body gamma irradiation by diltiazem. $\mathrm{Br} \mathrm{J}$ Radiol. 2007; 80: 77-84.

2. Maurya DK, Devasagayam TP, Nair CK. Some novel approaches for radioprotection and the beneficial effects of natural products. Indian $\mathrm{J}$ Exp Biol. 2006; 44: 93-114.

3. Arora R, Gupta D, Chawla R, Sagar R, Sharma A, Rajkumar, Prasad J, Singh S, Samanta N, Sharma RK. Radioprotection by plant products: Present status and future prospects. Phytother Res. 2005; 19: 1-22.

4. Emami B, Lyman J, Brown A, Coia L, Goitein M, Munzenrider JE, Shank B, Solin LJ, Wesson $M$. Tolerance of normal tissue to therapeutic irradiation. Int J Radiat Oncol Biol Phys. 1991; 21: 109-122.

5. Craft NE. Relative solubility, stability, and absorptivity of lutein and $\beta$-carotene in organic solvents. J Agric Food Chem. 1992; 40: 431434.

6. Bhagavathy S, Sumathi P. Evaluation of above 1.25 can have a potent impact on the survival and thus be considered as a radioprotector along with its other properties such as anti-inflammatory, antioxidant and anti-cancer property.

\section{ACKNOWLEDGEMENT}

The authors are grateful to the board of research in nuclear sciences (BRNS) for providing the funds to carry out the research work and to Nitte University for giving us the laboratory facility. The authors are thankful to Prof (Dr). Jayaram Shetty, Dept of Oncology and Alex John Peter, radiation physicist, Dept. of Oncology, K S Hegde Hospital; for providing the radiation facility. We are also thankful to the statistician Prof. Krishna Bhat for sparing his time with us for the statistical analysis of our results.

\section{CONFLICTS OF INTEREST}

The authors declare that they have no conflicts of interest. antigenotoxic effects of carotenoids from green algae Chlorococcum humicola using human lymphocytes. Asian Pac J Trop Biomed. 2012; 2(2): 109-117.

7. Sindhu ER, Preethi KC, Kuttan R. Antioxidant activity of carotenoid lutein in vitro and in vivo. Indian J Exp Biol. 2010; 48: 843-848.

8. Lee EH, Faulhaber D, Hanson KM, Ding W, Peters S, Kodali S, Granstein RD. Dietary lutein reduces ultraviolet radiation-induced inflammation and immunosuppression. J Invest Dermatol. 2004; 122: 510-517.

9. Van Poppel G, Verhoeven DT, Verhagen H, Goldbahm RA. Brassica vegetables and cancer prevention. Epidemiology and mechanisms. Adv Exp Med Bio. 1999; 472: 159-168.

10. Snodderly DM. Evidence for protection against age-related macular degeneration by carotenoids and antioxidant vitamins. Am J Clin Nutr. 1995; 62(6): 1448-1461.

11. Tice RR, Agurell E, Anderson D, Burlinson B, Hartmann A, Kobayashi H, Miyamae Y, Rojas E, Ryu JC, Sasaki YF. Single cell gel/comet 
assay: guidelines for in vitro and in vivo genetic toxicology testing. Environ Mol Mutagen. 2000; 35: 206-221.

12. Fenech M. Cytokinesis-block micronucleus cytome assay. Nat Protoc. 2007; 2: 1084-1104.

13. Xu W, Yang F, Shen X, Fan S, Liu Q, Wang D. Polysaccharide isolated from Parmelia tinctorum ameliorates ionizing irradiation-induced damage in mice. J Radiat Res. 2014; 55(4): 641-647.

14. Mozaffarieh M, Schoetzau A, Sauter M, Grieshaber M, Orgül S, Golubnitschaja O, Flammer J. Comet assay analysis of singlestranded DNA breaks in circulating leukocytes of glaucoma patients. Mol Vis. 2008; 14: 15841588.

15. Nair CK, Menon A. Consumption of antioxidant dietary agents, curcumin and vitamin C, protects cellular DNA from gamma-radiation. Int J Radiat Res. 2013; 11(1): 11-16.

16. Suzuki Y, Nagae Y, Li J, Sakaba H, Mozawa $\mathrm{K}$, Takahashi A, Shimizu H. The micronucleus test and erythropoiesis. Effects of erythropoietin and a mutagen on the ratio of polychromatic to normochromatic erythrocytes (P/N ratio). Mutagenesis. 1989; 4(6): 420-424.

17. Nadi S, Monfared AS, Mozdarani H, Mahmodzade A, Pouramir M. Effects of arbutin on radiation-induced micronuclei in mice bone marrow cells and its definite dose reduction factor. Iran J Med Sci. 2016; 41(3): 180-185.

18. Diab KA, Aida EL, Abd-Elmoneim OM, Sharaf HA. Assessment of genotoxicity and histopathological changes induced by polyethylene glycol (PEG6000) in male mice. J Cytol Histol. 2012; 3(5): 1000153.

19. O'Connell KE, Mikkola AM, Stepanek AM, Vernet A, Hall CD, Sun CC, Yildirim E, Staropoli JF, Lee JT, Brown DE. Practical murine hematopathology: A comparative review and implications for research. Comp Med. 2015; 65(2): 96-113.

20. Rosen EM, Day R, Singh VK. New Approaches to radiation protection. Front Oncol. 2015; 4: $1-15$. 